\title{
A holistic approach to the productivity paradox
}

\author{
Rune Wigblad $^{\mathrm{a}, *}$, John Lewer ${ }^{\mathrm{b}}$ and Magnus Hansson ${ }^{\mathrm{c}}$ \\ a Dalarna University College, Department of Economy and Society, SE-781 88 Borlänge, Sweden \\ Tel.: +46-23-778557 or +46-709-100594; Fax: +46-23-778052; E-mail: rwi@du.se \\ $\mathrm{b}$ The University of Newcastle, Employment Studies Centre, Faculty of Business and Law, NSW 2308, Australia \\ Tel.: +61-2-49-216814; E-mail: john.lewer@newcastle.edu.au \\ c Örebro University, Department of Economics, Statistics and Informatics (ESI), Fakultetsgatan 1, \\ SE-701 82 Örebro, Sweden \\ Tel.: +46-19-303971 or +46 709-450995; E-mail: magnus.hansson@esi.oru.se
}

\begin{abstract}
Both the public and private sectors have since the 1980s relentlessly cut the size of their workforces. The downsizing has regularly been reported to lead to closure of a whole or a part of a corporation or organization. Some studies which have analyzed the closures have reported that remarkable, counterintuitive improvements in labor productivity occurred during the time-period between the closure announcement and the final working day. Testing an elaborated cybernetic model on a Swedish case study, and on an exploratory basis, this paper proposes a holistic approach to generate a better understanding of this phenomenon. The main holistic pattern is a new order where management control is replaced by more "Self-management" on the plant level, and very strong psychological reactions based on feelings of unfairness.
\end{abstract}

Keywords: Closedown, cybernetics, downsizing, industrial relations, productivity

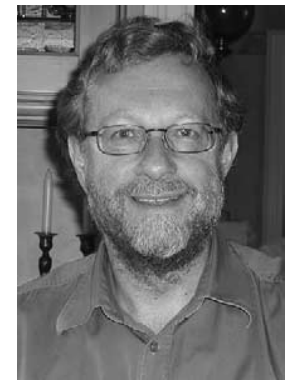

Rune Wigblad is Associate Professor in Engineering Management and is currently working at Dalarna University College, Sweden. Associate Professor Wigblad is also working as supervisor for doctoral students and has given several doctoral courses in scientific methodology, pragmatism, restructuring etc. His main research interest is in restructuring - early development of a restructuring model that also has been implemented in practice. The model concerns the re-build-up of new industry structure when factories close down operations. During that research he discovered the Closedown effect, the productivity increase that occurs during the process of organizational closedown.

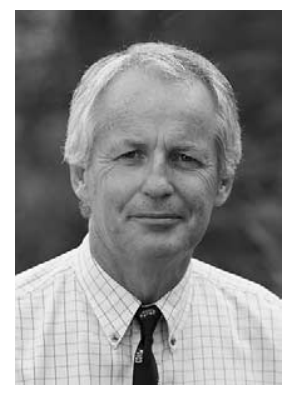

John Lewer, B.Com (UNSW), M.Com (UNSW), Dip Ed. (Sydney Teachers' College), PhD (Newcastle). Dr. Lewer is a member of the Organisational Studies and Employment Relations group in the Faculty of Business and Law at the University of Newcastle, Australia. His doctoral thesis investigated the remarkable performance by the workforce at a steelworks in Newcastle during the winddown period to the plant's closure. Apart from researching in the field of plant closure, his recent publications have considered the impact of socially responsible investment on human resource management and a critique of the institutional arrangement which determine the remuneration of parliamentarians, judicial officers and senior public servants in Australia.

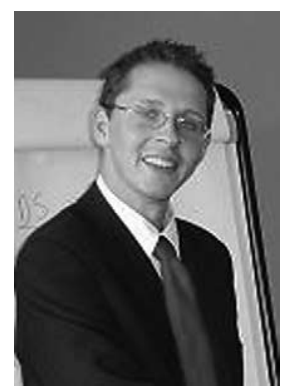

Magnus Hansson, $\mathrm{BSc}, \mathrm{MSc}, \mathrm{PhD}$ (Lic.) is a doctoral student and researcher at Örebro University in Sweden. He is member of Centre of Empirical Research on Organizational Control (CEROC). His primary research has been on organizational closedowns and in particular focusing on productivity effects during the process of closedown. He is also working as a lecturer in Strategy, Marketing, Organizational Theory and Research Methodology.

\footnotetext{
${ }^{*}$ Corresponding author.
} 


\section{Introduction}

Edith Penrose's book, the Theory of the Growth of the Firm [46] first published in 1959, captured much of the post World War II optimism of abundant, even limitless economic growth. In her analysis, few constraints were obvious, except, predominately, managers' capabilities to cope with uncertainty and risk. Such growth was underpinned by a social contract between capital and labour which secured increasing incomes and job security. White collar employees could realistically anticipate lifetime employment and, for blue collar employees, layoffs would occur only as a last resort to accommodate temporary cyclical downturns [49,53]. Generally organizations hoarded labour [20]. However, and commencing largely in the 1980s, an unabated wave of job losses, or "downsizing" has occurred as both private and public sectors relentlessly reduced the size of their workforces. Despite the evidence of Cascio, Young and Morris [21] and other dissenters who have extensively challenged the claim of performance improvements derived from downsizing, it still dominates much of the change in contemporary organizations. McKinley, Mone and Barker [40, p. 2] showed that in the USA during the mid-1990s, large companies were still reducing their "headcounts" by at least 5 per cent per annum (or at least twice the rate in the 1970s) finding that "downsizing is implemented in profitable organizations that do not face actual or impending revenue declines". Herein lies the historical break of downsizing from the layoffs and closedowns of the past; organizations cut jobs often in spite of profitable operations, improving or stable demand for their products and services and commonly in the absence of any apparent economic crises.

Under downsizing, firms and government agencies have rationalized activities, restructured, outsourced, shifted activities offshore and intensified worker effort sometimes, but not always, through productivity bargaining. Often, downsizing is directly focused solely on cost cutting, typically pursued by workforce reductions and the curtailment of investments in, for example, new production equipment. At its most extreme downsizing occurs when a production or service unit is closed, such as a hospital, mining operation, administrative section, transport facility or factory $[5,55$, p. 302]. The common feature of all closure events, irregardless of the type of the unit being closed, is that a temporary organization is created out of the previously permanent organization. This fundamentally reorders the organization's pre-existing social relations.
Closures are widespread. For example, in Australia, at least 30000 businesses close annually and, as a consequence, 100000 plus workers are retrenched [3,4]. US data for the year 2002 reported 302979 workers were displaced as a result of 1178 permanent worksite closures [19]. In Sweden 12191 full time employees (representing 19.8 per cent of all retrenchments) were displaced in 611 closures 2004 [51].

Job loss through downsizing and closure has severe adverse consequences on the displaced workers; most retrenched employees face periods of extended unemployment and often marginalized jobs at substantially reduced earnings [20]. A litany of personal negative effects, too, is commonly experienced by displaced workers; "shock, disbelief, anger, hurt, sense of powerlessness, loss of confidence and self-esteem" [56, p. 189]. Also, the burgeoning downsizing literature generally concludes that workers experience a changed and weakened psychological contract with their employer [48]. Disturbed by retrenchments, employees typically manifest their concerns in a raft of negative behaviors; reduced organizational commitment, skepticism, resistance to change, increased stress, lower productivity, poorer safety and a reluctance to facilitate innovation which is often referred to as the survivor syndrome [c.f., [7-15,22,27,34-39]]. Contrary to this concept, this paper explores a phenomenon called the "Closedown effect", with increased productivity during the closedown period [6,23-25].

Given the considerable impact closures have on employees, what performance levels should management anticipate from its workforce during the closedown period? That is from the time the announcement of the closure decision to the workforce and other stakeholders, until the operation's final day. Very few studies have been published which directly address this issue, which is odd given the extent and profundity of plant closures. Indeed as Sutton [50, p. 542] argued that much has been written about why organizations "die" but in contrast, little research or conceptual work focuses on how the process of organizational "death" unfolds. This paper addresses the question how performance changes during the closedown process and discusses possible explanations for these changes.

Managers who have planned closures have reported that they expected productivity would fall because workers, their collective agencies and possibly the wider community are dealing with resentment, future uncertainty and concerns over job loss [24,25,30]. However, contrary to these expectations, strong counterintuitive improvements in productivity have been 
recorded in some cases during the closedown period. Bergman and Wigblad [6] refer to this "unexpected, puzzling social phenomenon" as the "Closedown effect", for which a final explanation, they surmised, was yet to be found.

Defined, the Closedown effect occurs when, without any change to capital investment, a productivity increase is observed during the closedown period. It is recognized that labor productivity is difficult to define and to measure in all contexts, which adds complexity in the determination of the existence and extent of the Closedown effect. However, to be consistent with the reported case studies discussed later, productivity is taken as the firm's output volume per employee. This is also a practice based measure which makes comparisons before and after the announcement of closure decision, accurate. Additionally, any measurement of productivity, especially in manufacturing organizations, must be cautious of changes due to alterations in the number of product lines, product assortment and downtime due to maintenance [25].

The purpose of this paper is to propose and test a holistic approach to analyzing the closedown effect, as an alternative to the mainstream explanations which rely on an analysis of single cause-effect relations. We propose a dynamic model to better understand the phenomenon of enhanced labor productivity experienced during closures. The first section describes the key phases involved in closure events and briefly explains the range of management interventions which may be offered to ameliorate against the negative consequences of the shut down. Drawing on the review of the limited number of published studies in the second part, and using Buckley's [17] model of collective action and institutional structure, the third part seeks to synthesize these largely disparate studies. Using and extending a case study of the closure of a steel manufacturing plant in Sweden by Hansson and Wigblad [25] we assess the utility of the model.

\section{Phases and management interventions in the closure processes}

Closedown periods can range significantly both in terms of the notice given and the degree of predictability of the announcement. Minimum notice requirements can be prescribed by statutory and other regulations. Under the US Worker Adjustment and Retraining Notification Act (WARN) employers with 100 employees (or the equivalent) are generally required to provide 60 days' notice of large-scale retrenchments. Australia's Workplace Relations Act prescribes notification obligations on employers and sets minimum redundancy entitlements. In Sweden, the Act of Codetermination at Work requires that the County Labor Board be notified of cutbacks which affect at least 25 employees. This Board and the local trade unions are to be notified 5-6 months in advance. Trade unions in Sweden also have rights to engage a Wage Earner Consultant who has the power to investigate and report on management's decision. The report may incorporate alternatives to closure. Actual closedown periods, world wide, can range from a few days, particularly for those small organizations beyond the reach of statutory requirements, to very extensive periods. When, for example, a steelworks in Newcastle, Australia was closed, the amount of notice given by the firm was two and a half years [30].

After the public announcement a closure, negotiations can occur in which the workforce and unions seek to resist the closure and/or achieve redundancy and other benefits from the employer. Hansson and Wigblad [25] define this negotiation phase as the advance notice period. When it is finalized, which again varies between cases, the end of the closedown period is defined as the countdown period (ibid.). Combined, the advanced notice and countdown periods form the closedown period.

Apart from the differing amounts of time from the announcement of the closure until the final day, it is also useful to differentiate between closures using as a criterion the extent of management assistance made available to the workforce and, sometimes, the wider community. It is possible to construct a continuum with at one extreme extensive, well-resourced adjustment and redundancy support programs and, at the other extreme, the minimum legal entitlements. Hansson and Wigblad [25] label these opposite poles as "socially" and "non-socially-responsible".

\subsection{The Closedown effect: possible explanations from the reported cases}

A vast minority of reports focus on how the process of organizational closedown unfolds. No theoretical analysis which integrates the differing accounts for the productivity improvements in the closing organization has yet been published. Proposed explanations for the Closedown effect specifically, are ad hoc. Some focus on workers' psychological response viz.; workers in closure contexts are motivated to set free previously 
held back performances because of a heightened pride in their job, a need to show that management made the wrong decision, a belief that the life of the plant may be prolonged and a concern that they will receive ideal references to assist with their search for future employment $[6,16,23,25,50]$. Designed to act as a psychological incentive, bonus systems based on output and additional payments made at the time of the closure have been noted in some cases [30,61].

Bergman and Wigblad [6, p. 348] considered these explanations of the Closedown effect as too psychologically focused. Analyzing the causes of Closedown effects solely on the employees' "mental states is not satisfying [...]. Collective actions in declining organizations obviously have social aspects related to the context in which they take place which must be considered in any serious explanation". Their research does not dismiss the explanatory power of workers' (sociopsychological) reactions outright though; accepting that falls in productivity after a closure is announced may be recovered when the initial anxiety, stress and anger are lowered. Furthermore it does not matter as much if the factory is run down without maintenance, and the plant usually is destinated for a changed assortment to be produced during the countdown period. In the Hammar Glass-Mill case Wigblad [59, pp. 103104] reported that his interviewees spoke of the "old pride in the craftsmanship in the plant", of the "unity" and "good spirit" in the company town, "self-esteem to perform reasonably well" and of few workers feeling the need for "revenge". However, Bergman and Wigblad [6, p. 365] have also argued that the labour process, the degree of management support in overseeing the closure and the actors' past and present experiences need to be strongly factored into any explanation.

Empirical work by Bergman and Wigblad [6]; Lewer [30]; Brown et al. [16]; Hansson [23]; Hansson and Wigblad [25] showed that a changing frontier of control between labour and management in the altered conditions brought about by the closure announcement, facilitated more productive work conditions. In effect, managers "retreat" from the field thereby providing greater autonomy to the workforce. Sometimes this is necessitated as workers leave and are not replaced during the closedown period. This provides opportunities for the development of innovative skills, extension of job-sharing arrangements, improved informal leadership and self-organizing work groups, while planning is deployed to the lower levels in the hierarchy. Significantly less formalized work patterns commonly emerge.
Most studies have involved manufacturing firms where there has been a strong worker collective and often a socially responsible managerial response to the closure. Here, explanations of the closedown effect have been found in context-specific dimensions such as "best practice" management [16], and "excellent" retrenchment programs involving retraining opportunities, early retirement programs, job search aid, severance payments and bonus programs [6,23,30,58, 59]. The Closedown effect has also been observed in non-socially-responsible cases [26,27,50]. Hansson and Wigblad [25] have published research of four nonsocially responsible closedown cases which demonstrated that after an initial downturn in productivity during the advance notice period, subsequently upturned in the countdown period. For obvious reasons there are no capital investments in closedown factories. Influence on productivity from investments can therefore be excluded.

\section{Framework}

Overall, it is clear from the research outlined in the preceding section that the Closedown effect is a complex social phenomenon - a phenomena where productivity improvements are not a function of changes in investments. The closedown effect which occurs under a variety of conditions and operates across an interlinked set of individual, group, organizational and institutional dimensions. Plus, the interaction between these elements is dynamic, i.e., changing during all the phases of the closure. As stated in the introduction, this paper proposes a more holistic approach to the Closedown effect as an alternative to the single cause-effect relations informing earlier explanations.

When looking for a model or theory that is truly socio-cultural and capable of analyzing conflict related contexts like the closedown, we note that the dominant theoretical perspectives are referred to variously as equilibrium, consensus or functional theory. The classical idea of Pareto which typically underpins these perspectives is of an optimum whereby the "system" may be in a state of "equilibrium". The Pareto idea of society as a "system" of interrelated parts operating with defined boundaries that typically tends to equilibrium, was expounded by Bukharin [18], Sorokin [47], Znaniecki [62], and Lewin [31-33], among others. Furthermore the common denominator in the functionalist system models is the stipulated idea of equilibrium. This idea dominates the work of influential sociologists 
like Parsons [43-45] and Homans [28,29] and concerns "checks and balances", "countervailing power" and "inertia".

In contrast to these traditions, some cybernetic thinkers take the appearance of disequilibrium as the analytical focus, seeing equilibrium as a temporary state. An open system in the cybernetic tradition is here defined as having "disequilibrating" capacity or, to use Buckley's metaphor, they are "negentropic". The metaphor "entropy" comes from natural science and is connected to the second law of thermodynamics. The point made is that open social systems tend to increase in entropy [17], i.e., they are tending towards disequilibrium. Instead of focusing on single cause-effect relations, cybernetics has developed holistic feedback models which link structure to dynamic events which, in turn, further change the structure [1,2,17,52,54,57]. For instance, von Bertalaffy's concept of “equifinality" asserted that the same end-state can be obtained in several different ways. However, in closedowns events, differing end-states have been observed. Buckley's [17] systems theory model (see Fig. 1) recognizes these varying end-states; defined by Buckley as "multifinality". Combining classical institutionalization theory (mainly Max Weber) with social psychological interactionist theories (mainly G.H. Mead [41,42]), Buckley's work facilitates an analysis of the changed institutional order which could arise from dramatic events, a fact which makes this theory interesting for the context of closures. The Buckley feedback-controlled sys-

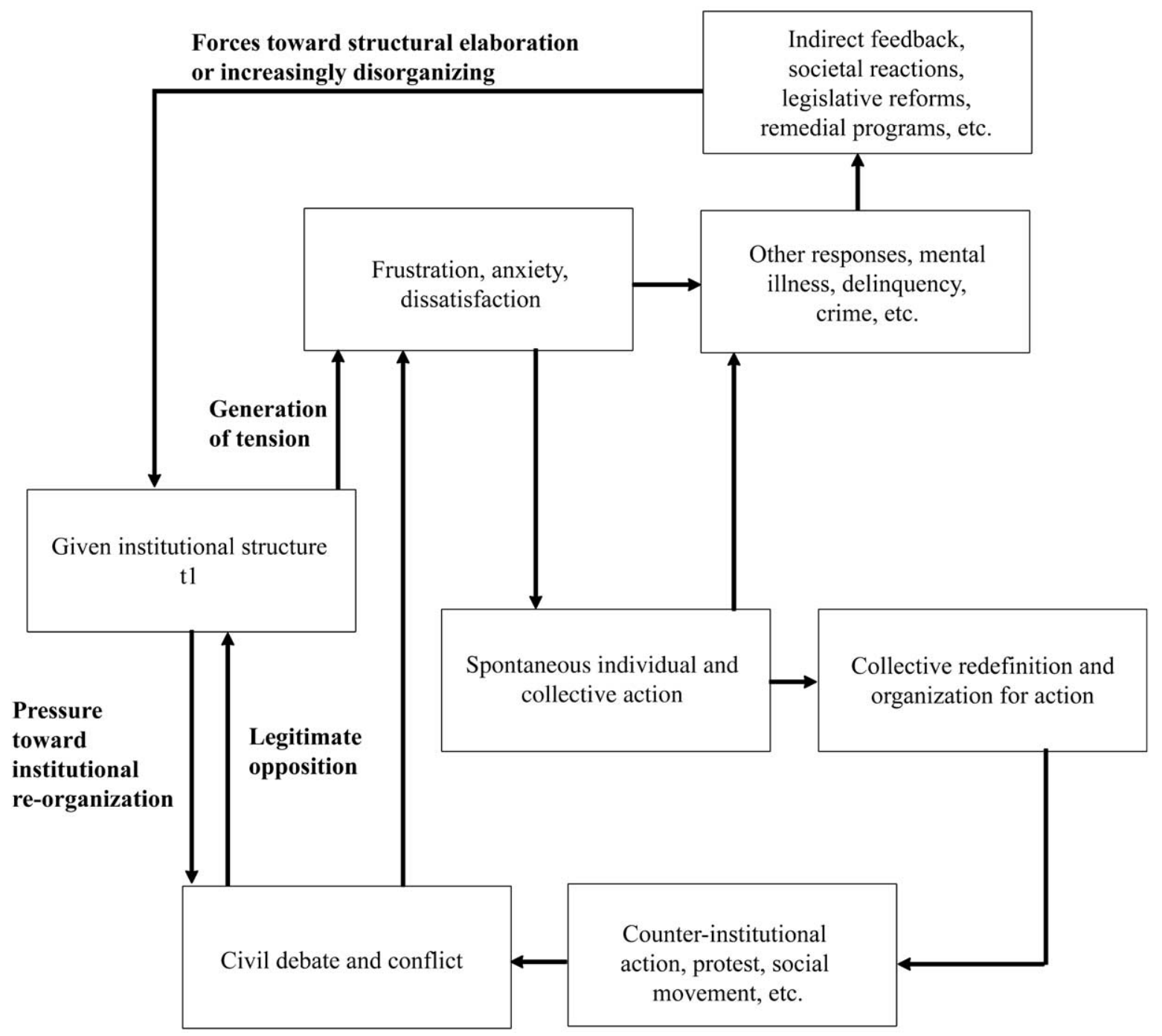

Fig. 1. Buckley's [17, p. 138] simplified systemic view of the "collective behavior". 
tems are referred to as goal-directed, since it is deviations from the goal-state itself that direct the behavior of the system, rather than some predetermined internal mechanisms that aims blindly. The focus on feedback mechanisms challenges the oversimplified notion of one-sided cause-effect relationships. We hold that it is not possible to point out one single factor causing the Closedown effect. The complex phenomena under study calls for a feedback model addressing the total socio-cultural system in the context analyzed (see Fig. 1).

One core element of Buckley's model, as shown in Fig. 1, is "system tension" or, "strain", on individuals. This tension may diminish or be exacerbated through changes in the institutional structure. Buckley [17, p. 51] explicates "tension", of which "stress" and "strain" are manifestations, to be ever present in one form or another throughout the sociocultural system. Examples of tension are socially unstructured strivings, frustrations, enthusiasms, aggressions, neurotic or normative deviation, crowd or quasigroup processes [17]. In the closure context and related events, strain is commonly manifest as worry, anxiety and insecurity for the affected individuals over their future employment, possibly worsened if the employee feels isolated, or unsupported. Also, central to the model are "purposive systems" and "feedback loops". For purposive systems goals are explicit, conscious and intentional. Social feedback models have been suggested by a few scientists like Vickers, Deutsch and Easton. Based on such purposive systems analysis the feedback loops in the Buckley [17] model illustrates the modifications and effects on goals as the actions are carried out.

The feedback loops in Fig. 1 are twofold, viz. the structural elaboration loop and the reorganization loop. The "closed circuit feedback" is not obviously visible in Fig. 1, but it does not affect the institutional and economic structure at all, since it is feeding back on itself with the further progression in the model, i.e., internalization of the strain. Such halts in the further progression of feedback loops can appear between all feedback boxes in Fig. 1. The structural elaboration/disorganizing feedback loop on the other hand is a first order change trigged by the initial strain, developing through the causal chain from individual reactions to more collective actions which creates pressure to change the institutional structure. The reorganization feedback loop is a second order change that reorders the given institutional and economic structure, also developing from strain on individuals to group ac- tions. The reorganization feedback emanates from two sources, the legitimate opposition and/or collective organization for action.

The concept of "given institutional structure" in the Buckley model needs to be further elaborated for our purpose to understand the Closedown effect. The limitation of Buckley's [17] model of collective behavior is its abstract character, leaving the sources of intentionality and meaning unexplained. We argue that this weakness in the model can be managed if context specific intentionality and meaning is included. Closedown situations represent a context where the management intentionally has established a pressure towards economic restructuring, which puts much more focus on the economic structure. Economic situations differ, which influence the decision maker's ability and willingness to make short-term sacrifices for the possibility of long-term gains. Economic decision makers can be either short-terminist or long-terminist. When including corporate economic measures, productivity becomes important. It is both a new institutional structure and a new economic effect on the organizational level that is the focus of our paper. We therefore adjust the Buckley model so that "given institutional structure" is interacting with the "given economic structure" and management intentions connected to this structure.

Buckley's purpose was to elaborate how institutions create strain among people on a macro level of analysis and did not address single organizations economic tensions and outcomes. We therefore define the system boarder for the economic structure as the corporate organization.

The given economic structure can in itself be viewed as a state that is altered, dynamically. The dynamics involved includes elaboration and restructuring by feedback loops connected to the interplay between the company management, its competitive environment and the rest of the institutional structure. We therefore add the economic structure to the Buckley model as illustrated in Fig. 2.

The principal dynamics in Fig. 2 is that the given institutional structure at time $t_{1}$ is seen as a temporary state of economic and labour-management relations based on past events. In the closedown case the $t_{1}$ is based on the "prenotice period" where top management is deciding on the timetable for the closedown. Management is in the closedown situation putting pressure towards restructuring for economic reasons, with the ambition of increasing profitability. This institutional structure $t_{1}$ is reordered by the feedback loops into new institutional structures $t_{2}, t_{3} \ldots t_{n}$. Applying 


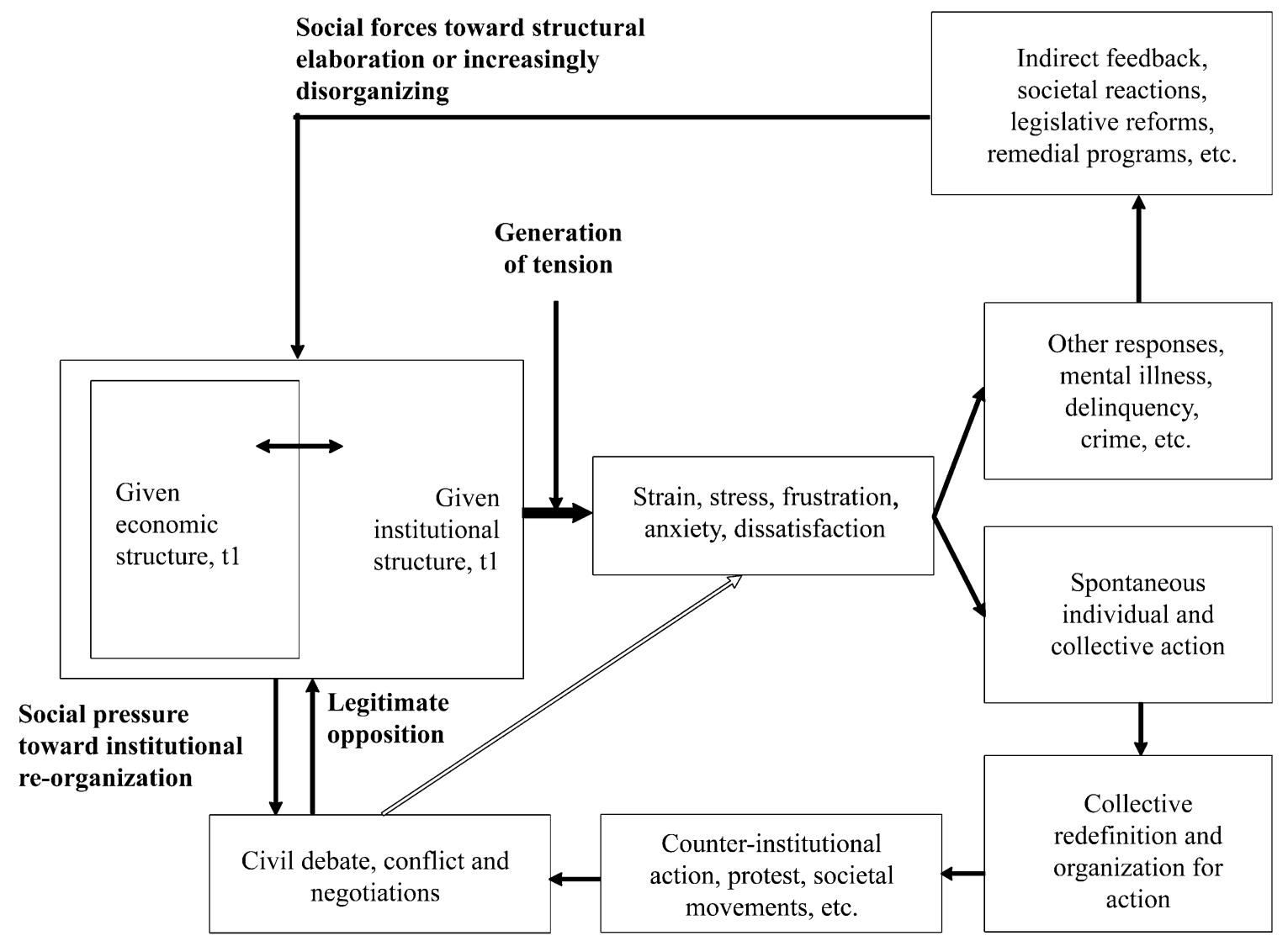

Fig. 2. A dynamic model of economic and institutional change on the organizational level of analysis.

this more precisely in the closedown situation the time point $t_{1}$ marks the public announcement of the decision to close down. The time between $t_{1}$ and $t_{2}$ is related to the advance notice period and the time elapsed between $t_{2}$ and $t_{3}$ is the countdown period. The structure of the system is thus viewed in terms of sets of alternative actions, associated with the components and the constraints that specify, or limit, these alternative actions.

\section{The Fundia Steel Wire Rod case study}

On 16 October 1998, the Group Fundia announced that its Rod wire mill located in Smedjebacken, Sweden, would be closed as part of a restructuring in Fundia Steel, top management suggesting the concentration of the rod bar production to its "Mo i Rana" (Mo) plant in Norway. It was an insecurity for the steel workers if they should be able to get new job opportunities on the local labour market in Smedjebacken, due to the relatively high level of unemployment in the local com- munity. The best opportunity for some of them was job transfer to the two remaining plants in the Fundia location in Smedjebacken. The closedown period of the Wire Rod Mill was about 33 weeks. Negotiations took place with the unions for about twelve weeks, the advanced notice period. Thus the countdown period was approximately 21 weeks. In terms of productivity, in 1998, the Smedjebacken plant's rate of 44 tones per hour (tph) compared with an average of approximately 58 tph in the "sister" Norwegian plant. As the Norwegian plant had more modern technology the economic intention of the restructuring plan was to close down the low productivity plant in order to increase the total productivity across the Group.

The closedown had initially non socially-responsible characteristics because the local trade union, with the help of a Wage Earner Consultant, had presented an economically viable alternative, challenging the calculations Fundia's management had used to justify the closure. Swedish labor legislation includes collective bargaining, as discussed earlier, entitles the affected union to engage a Wage Earner Consultant as a third 


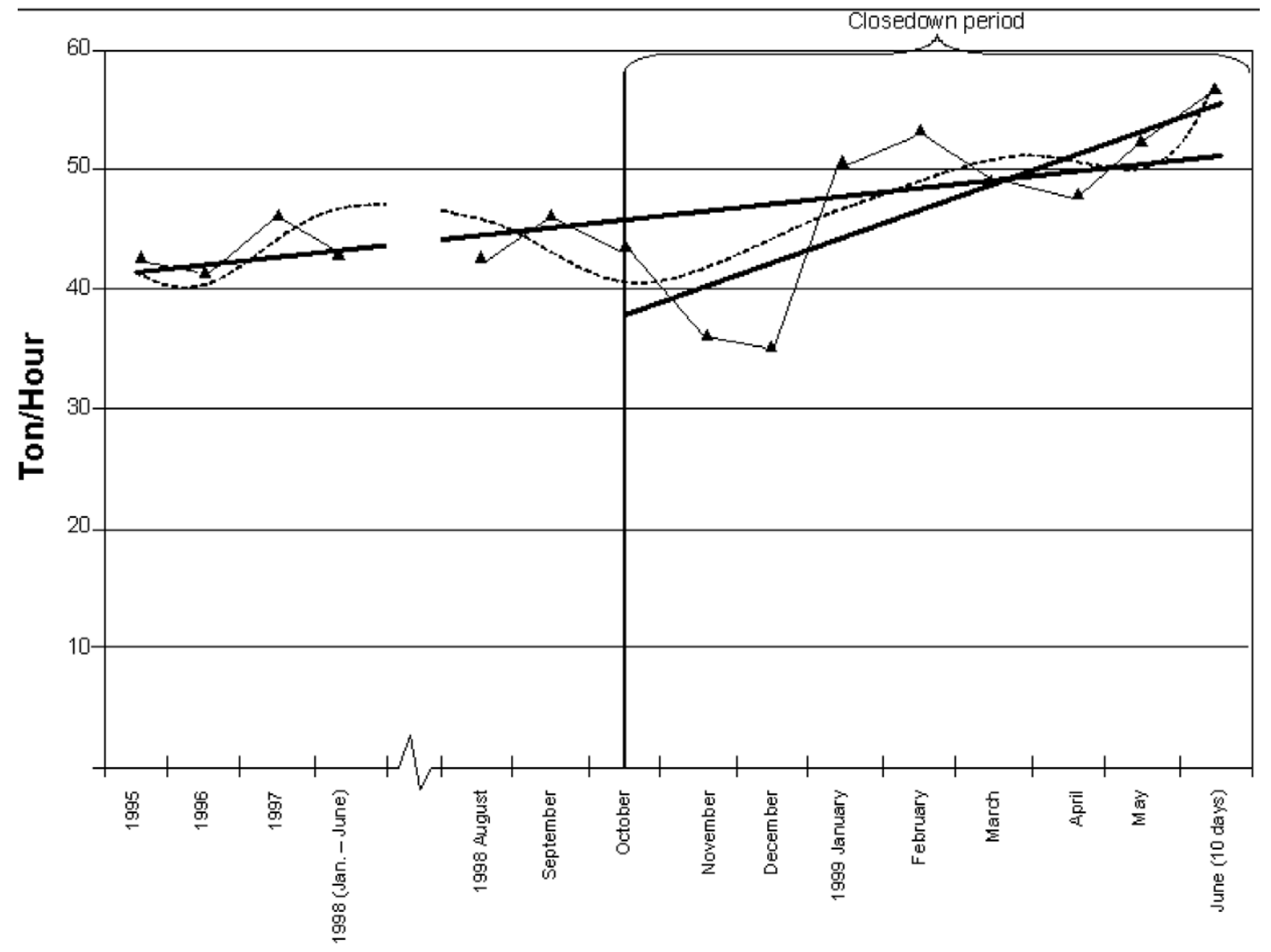

Fig. 3. Production rate at Fundia Steel Wire Rod plant, 1998-1999.

party, to evaluate and critically review the decision to close the plant. The collective bargaining position of Swedish trade unions is comparably strong because of a high degree of unionization and the existence of collective agreements. Summarizing, the wage-earner consultant's report contended the Smedjebacken plant operations could be prolonged if the fifth shift in the Norwegian plant was discontinued. In effect, the fifth shift at Mo was found far less profitable than the Smedjebacken operation. A prolongation of the Smedjebacken plant would win adjustment time for other measures taken, to increase expansion in the local community. Despite this wage-earner consultant's report [60], the Fundia board did not change its decision; instead it produced a counter-arguing report.

The firm planned to have the Smedjebacken plant markedly increase its production of the slowest to produce rods $(8 \mathrm{~mm})$ during the closedown period. The product would then be stockpiled. Management budgeted on a production rate $38 \mathrm{tph}$, during the close- down period for the purposes of their revised calculations, in effect, was slowing the plant down due mainly to changes in the product lines being manufactured. In other words, management altered the plant's production assortment compared to normal and in effect its efficiency, to legitimate the original closure decision. This new management report concluded that the fifth shift in Mo was more profitable, compared to Smedjebacken based on the 38 tph assumption. The final decision, after negotiations, to close down operations at Smedjebacken was made in the end of January 1999 with the operation finally terminated in June 1999. The strong position of the Wage Earners' Consultant's report and the alternative calculations however provided the local trade union with a bargaining position and the workers received bonus and severance payment, which makes this closedown case somewhat closer to a SRcase in this respect.

Figure 3 illustrates the productivity changes over time. Initially, during the advanced notice period (mid- 
October to late December) productivity fell. However, as Fig. 3 shows, after the negotiations had been concluded, the plant experienced the Closedown effect with productivity trending upwards during the five months of the countdown period, achieving a mean production rate of $50 \mathrm{tph}$. This compared with a mean 44 tph, prior to the closure announcement. When compared to the company's budgeted $38 \mathrm{tph}$, which is the most appropriate comparator, the outcome of the Closedown effect, was 29 per cent above target. Importantly, the number of blue collar workers did not change during the period from July 1998 to June 1999.

There is a need for a parallel analysis of two distinctive periods. The first interception is a trend extrapolation based on the period prior to the closedown decision and the second refers only to the closedown period. For that reason we conducted a subgroup analysis considering the period prior the closedown decision and the period after the closedown decision. The test for parallelism indicate a statistically significant Closedown effect $(T=26.532, \delta=7.37$ ), mainly during the countdown period.

Given the Closedown effect noted, it is relevant to stress the fact that the announcement of a closedown is not part of a deliberate management tactic to induce the effect. The closedown decision resulted from a downturn in the wire rod market, due to the crisis in Asia, which made it impossible for European steel manufacturers to sell wire rods into that market as they had done before the crisis. Europe was facing an over capacity problem.

The research determined that a number of factors were at work, all underpinning the extensive rise in Closedown effect. Individually, the workers were unsure who and how many would be offered employment in the same location, but in another production unit. None of the interviewees reported that they were anxious to ensure that they received a good referral or reference from their employer; ultimately 8 out of 33 were made redundant. Notably, and different from most other closedown cases, no monetary incentives such as productivity related bonuses were paid. Collectively, the workers expressed their sense of hurt pride and were motivated to prove to the Fundia that their 38 tph estimate was wrong. Some reported, for instance: "Let's show management that we can do better than 44 tones per hour - it's unfair to close down this plant". Others believed exceptional performance may save the plant, commenting that "most of us did not think that the production would be terminated" and "we're not finished before the last shift is ended". To our experi- ence this eternal hope is however unjustified in most cases, as it was in the Fundia case. There is usually a lot of management prestige involved, forcing them to stay put with the initial plan. For the trade unions, they were able to negotiate from a favorable position, leveraging off the Wage Earners' Consultant's report to gain a human resource program incorporating retraining, early retirement, job search aid and severance payments, but not bonus payments.

Management control faded during the countdown period allowing far greater flexibility. It became easier to make decisions on the shop floor concerning operative decisions on how to run the production process. More informal work practices developed especially following the appointment of a shop floor foreman as the plant manager. Changeover and start-up times were reported in a number of cases to have been reduced by $10-15$ minutes and 15 minutes respectively. They also noted a more efficient handling of breakdowns and necessary maintenance. Some temporary job sharing activities took place to allow workers time "off-site" for education programs. However, overall, no workers left permanently prior to the shut down. So, how does the modified Buckley model (Fig. 2) apply to the Smedjebacken case study?

Top management launched a restructuring plan to enhance productivity trigged by the market downturn. Following the closedown announcement, the unions restructuring alternative gave new hope in Smedjebacken. The first order feedback loop illustrated in Fig. 4 did however not result in a restructuring according to the economically viable alternative that the trade unions proposed.

The trade union bargaining position resulted in a new situation $t_{2}$ that trigged a second order feedback loop with the HRM-programs, illustrated in Fig. 5. The resulting debate concerning alternatives gave trade unions a substantial set of human resource management-styled support. A new plant management scheme was also negotiated for operations during the countdown period, which resulted in significantly less management control.

\section{Analysis and conclusions}

Analyzing the reordering of the organizational and economic structure in the Smedjebacken case reveals how the closedown decision, because of the strain that it introduced, knocked out the established productivity equilibrium into a state of steeply declining productiv- 


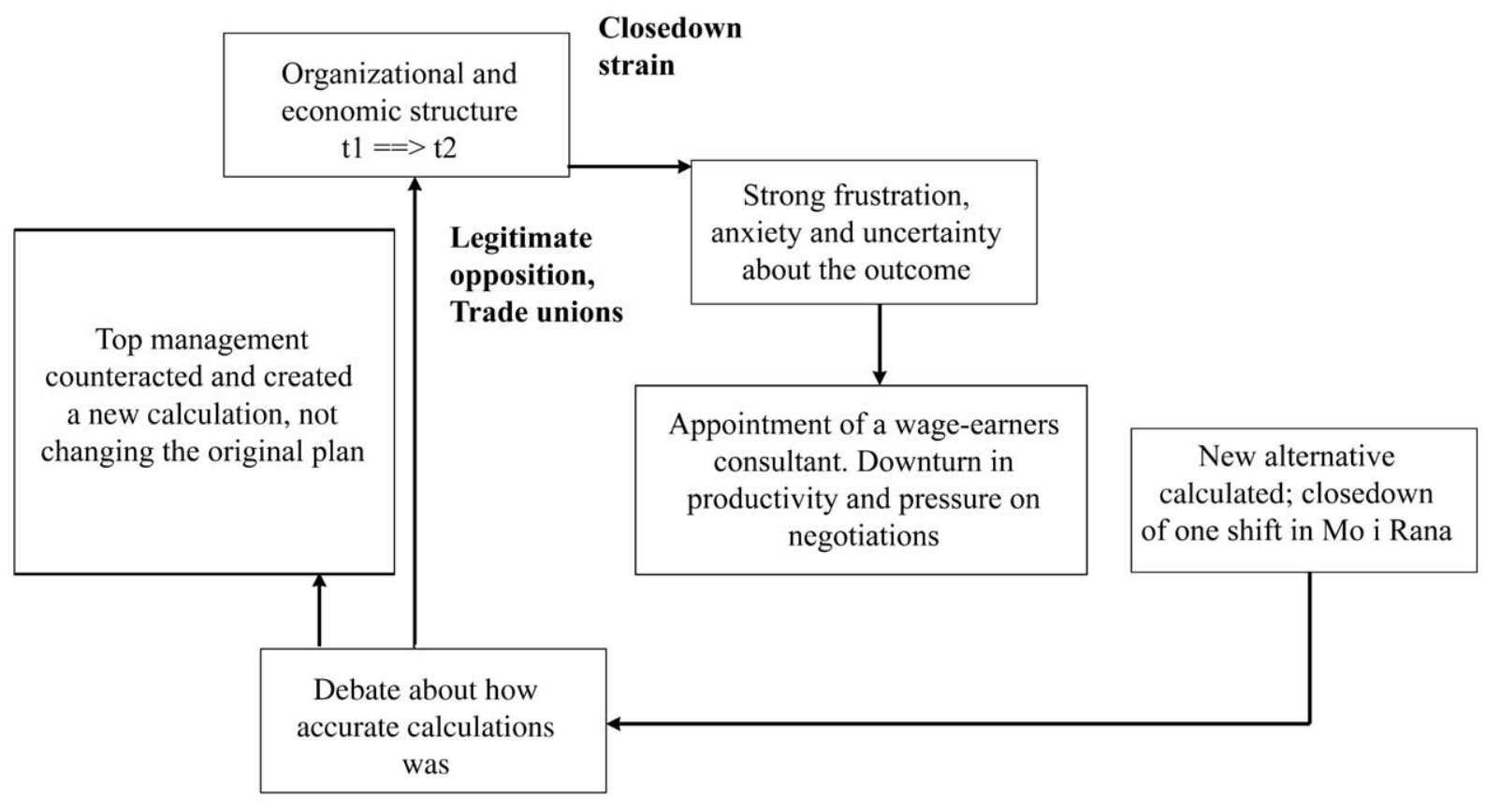

Fig. 4. The "blind feedback loop" during the advance notice period at the Wire Rod plant.

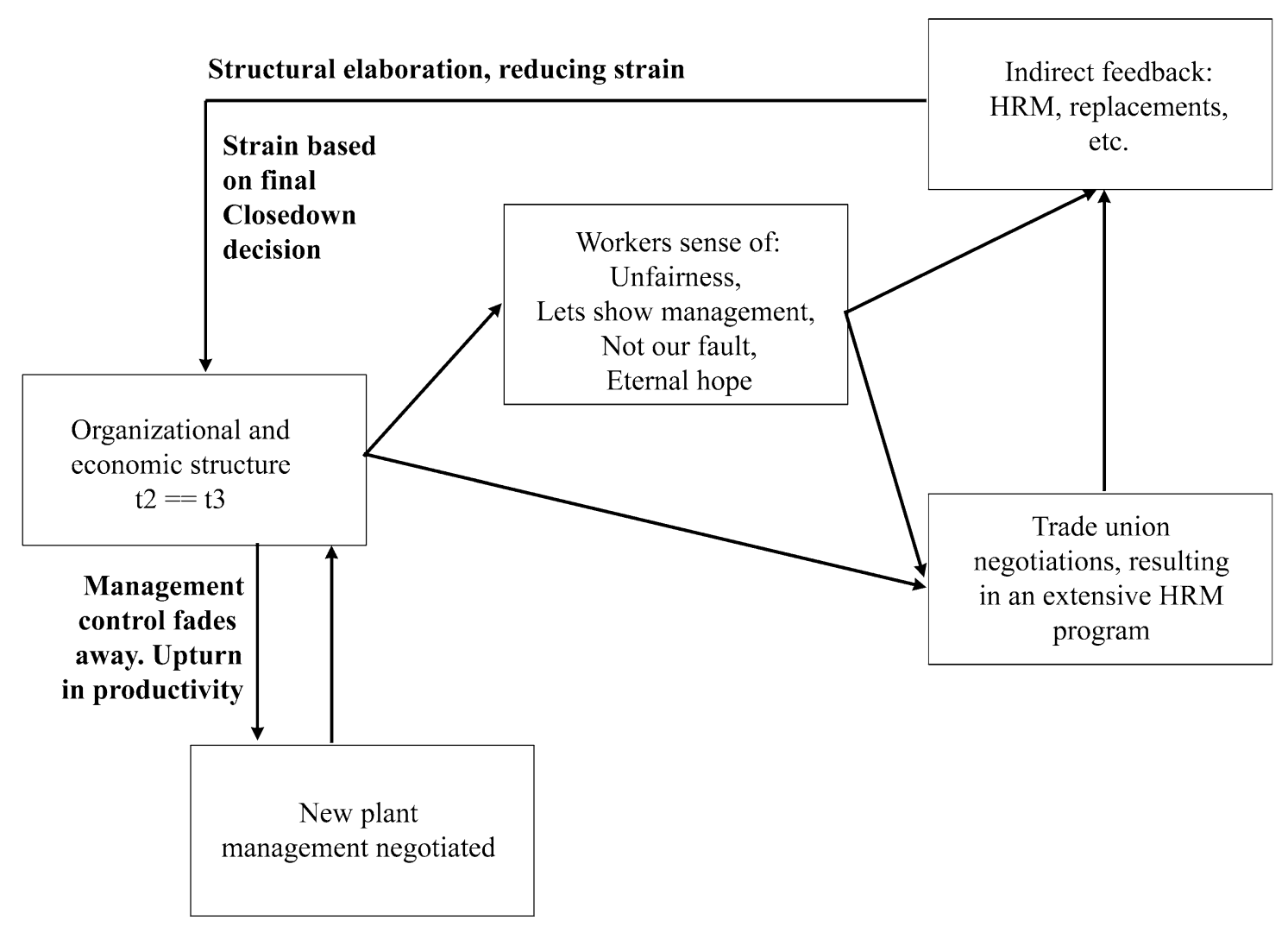

Fig. 5. The feedback loops in the countdown period at the Fundia Steel Wire Rod plant. 


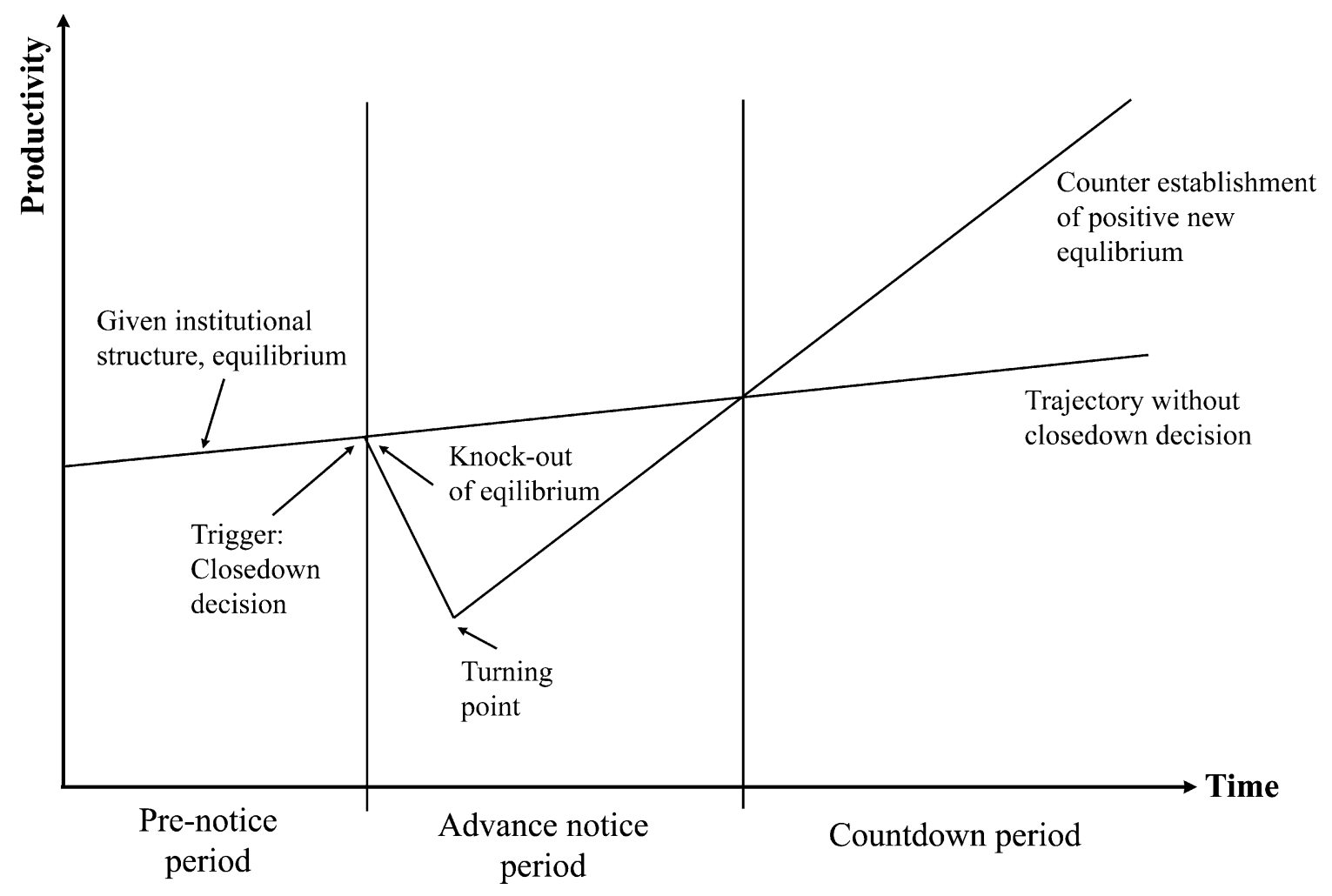

Fig. 6. The economic reordering into the closedown equilibrium.

ity (Fig. 6). This initial downturn in productivity put pressure on plant-level negotiations during the advance notice period, a pressure which was heightened by the release of the viable alternative set out in the Wage Earners' Consultant's report. The following agreement by the firm to only provide a socially-responsible set of human resource management interventions, to some extent moderated the strain, thereby providing the turning point and setting the conditions in place for the much steeper productivity trajectory. During the countdown period, the previous management constrains on the work groups were removed.

We have labeled Fig. 6 as the "economic reordering into the closedown equilibrium" illustrating the fundamentally new economic order during the closedown period. This new order is trigged by the closedown decision and the ideal-typical pattern is the "hockeystick" illustrated in Fig. 6.

After the initial knock out of economic equilibrium in the beginning of the advance notice period, we have in Figs. 4 and 5 been able to identify a pattern of social dynamics - over time where a variety of factors come into play. The overall dominating pattern is that top management by the closedown decision has de- prived themselves from their control possibilities. At first during the advance notice period they still have bargaining power and can reject propositions from the shop floor and at the same time the workers react by lowering their performance to put pressure on negotiations. In our case this however created a blind feedback loop, not influencing the institutional structure, only the economic structure. During the countdown period the management control fades away totally and the temporary new organizational and economic order is established which alter the system tensions into constructive measures that set free previously held back performance and increased creativity on the shop floor, resulting in a strong increase in productivity. The main pattern in the new order is that management control is replaced by more "Self-management" on the plant level, and very strong psychological reactions based on the unfairness feeling. Underlying is the disagreement concerning the close down decision, the decision counteracted on the shop floor with possible means characterized by comments such as "let's show them". The new temporary order that is established during the countdown period is only local and is by no means re- 
ordering the institutional structure on the labour market in Sweden.

Each closedown process has a set of unique characteristics in the way it unfolds. The dynamic modeling applied on our case study put these factors into perspective, increasing our understanding of the puzzling phenomena, the Closedown effect. Since the variables are interrelated we have illustrated how clusters of variables can be linked together in a comprehensive model that does not reduce the contextual complexity into one single variable or one single cause-effect relation. This provides a better understanding concerning what clusters of variables are influencing the changes in productivity and the strong Closedown effect during the countdown period. Plus, the model integrates the individual, collective and economic/institutional dynamics.

Since the model is applied on only one single case, it is tentative and therefore there is a need to verify or falsify this model. Each of our empirically found characteristics/variables included in the dynamic model may offer some explanatory possibility, for the manner in which the closure unfolds. Understanding the mechanisms involved that creates the Closedown effect, how single cause-effect relations reinforce the effect, we have learned that this effect is built up by forceful systemic blocks in real cases.

\section{References}

[1] C. Argyris, Action Science, Jossey-Bass, San Francisco, CA, 1985.

[2] W.R. Ashby, A Design for a Brain, Wiley, New York, 1952.

[3] Australian Bureau of Statistics, Further Developments in the Analysis of Productivity Growth in Australia, Australian National Accounts: National Income, Expenditure and Product, Catalogue No. 5206.0, Canberra, 2001.

[4] Australian Bureau of Statistics, Retrenchment and Redundancy, Catalogue No. 6266.0, Canberra, 2002.

[5] J.R. Baldwin, Death in the Industrial World: Plant Closures and Capital Retirement, Statistics Canada, Ottawa, 2005.

[6] P. Bergman and R. Wigblad, Workers' last performance: Why some factories show their best results during Countdown, Economic and Industrial Democracy 20 (1999), 343-368.

[7] J. Brockner, Managing the effects of lay-offs on survivors, California Management Review 34(2) (1992), 9-28.

[8] J. Brockner, S. Grover, T.F. Reed and R.E. DeWitt, Layoffs, job insecurity, and survivors' work effort: evidence of an invertedU relationship, Academy of Management Journal 35(2) (1992), 413-425.
[9] J. Brockner, J. Greenberg and S. Grover, The impact of layoffs on survivors: Insights from interpersonal and organizational justice theory, in: Advances in Applied Social Psychology: Business Settings, J. Carrol, ed., Hilldale, NJ, 1988, pp. 267-288.

[10] J. Brockner, S. Grover and M. Blonder, Predictors of survivors' job involvement following layoffs: A field study, Journal of Applied Psychology 73(3) (1988), 436-442.

[11] J. Brockner, The effects of layoffs on survivors: Research theory and practice, Research in Organizational Behavior 10 (1988), 213-255.

[12] J. Brockner, S. Grover, T. Reed, R.-L. DeWitt and M. O'Malley, Survivors' reactions to layoffs: We get by with a little help for our friends, Administrative Science Quarterly 32 (1987), 526541.

[13] J. Brockner, J. Greenberg, A. Brockner, J. Bortz, J. Davy and C. Carter, Layoffs, equity theory and work motivation: Further evidence for the impact of survivor guilt, Academy of Management Journal 29 (1986), 373-384.

[14] J. Brockner, J. Greenberg, A. Brockner, J. Bortz, J. Davy and C. Carter, Layoffs, equity theory, and work performance: Further evidence of the impact of survivor guilt, Academy of Management Journal 26(2) (1986), 373-384.

[15] J. Brockner, S. Grover, M. O’Malley, T.F. Thomas and M.A. Glynn, Threat of future layoffs, self-esteem and survivors' reactions: Evidence from the laboratory and the field, Strategic Management Journal 14 (1985), 153-166.

[16] K.A. Brown, T.G. Schmitt and R.J. Schonberger, A longitudinal study of a plant closure: Employee responses and performance, in: Academy of Management Annual Meeting, New Orleans, August, 2004.

[17] W. Buckley, Sociology and Modern Systems Theory, Englewood Cliffs, NJ, 1967.

[18] N. Bukharin, Historical Materialism: A System of Sociology, International Publishers, New York, NY, 1925.

[19] Bureau of Labor Statistics, Extended Mass Layoffs in 2002, US Department of Labor, Report No. 971, 2003.

[20] P. Cappelli, L. Bassi, H. Katz, D. Knoke, P. Osterman and M. Useem, Change at Work, Oxford University Press, New York, NY, 1997.

[21] W.F. Cascio, C. Young and J.R. Morris, Financial consequences of employment-change decisions in major U.S. corporations, Academy of Management Journal 40(5) (1997), 1157-1189.

[22] D. Guest, Is the psychological contract worth taking seriously? Journal of Organisational Behavior 19 (1998), 649-664.

[23] M. Hansson, When the lights go out, in: Proceedings of the European Academy of Management (EURAM), St Andrews, Scotland, 2004.

[24] M. Hansson, From Dusk 'til Dawn: Three essays on organizational Closedowns, Unpublished dissertation, Örebro University, Sweden, 2005.

[25] M. Hansson and R. Wigblad, Pyrrhic victories - anticipating the Closedown effect, International Journal of Human Resource Management 17(5) (2006), 938-958.

[26] C. Hardy, Managing Organizational Closure, Gower Publishing, Aldershot, 1985.

[27] C. Hardy, Investing in retrenchment: Avoiding the hidden costs, California Management Review 29(4) (1987), 111-125. 
[28] G.C. Homans, The Human Group, Routhledge and Kegan Paul, London, 1951.

[29] G.C. Homans, Social Behavior: Its Elementary Forms, Routhledge and Kegan Paul, London, 1961.

[30] J. Lewer, Strategic HRM and organisational performance under extreme conditions: A case study of plant closure, in: Conference Proceedings, Challenging HRM Conference, Nijmegen, Netherlands, November, 2001.

[31] K. Lewin, Principles of Topological Psychology, McGraw-Hill, New York, 1936.

[32] K. Lewin, Feedback problems of social diagnosis and action. Part II-B of frontiers in group dynamics, Human Relations 1 (1947), 147-153.

[33] K. Lewin, Field Theory in Social Science: Selected Theoretical Papers, Tavistock, London, 1952.

[34] C.R. Littler and M. Hansson, Are Closedown plants highperformance workplaces? Untangling a theoretical paradox, in: Conference Proceedings, British Academy of Management Conference, University of Oxford, UK, 2005.

[35] C.R. Littler and P. Innes, Downsizing and deknowledging the firm, Work, Employment and Society 17(1) (2003), 73-100.

[36] C.R. Littler, R. Wiesner and R. Dunford, The dynamics of delayering: Changing management structures in three countries, Journal of Management Studies 40(2) (2003), 225-256.

[37] C.R. Littler, Case studies of the finance sector and BHP, Newcastle, in: Conference Proceedings, Big Issues for Big Business, University of Melbourne, 1999.

[38] C.R. Littler, T. Bramble and J. MacDonald, Organizational Restructuring: Downsizing, Delayering and Managing Change at Work, AGPS, Canberra, 1994.

[39] C.R. Littler, R. Dunford, T. Bramble and A. Hede, The dynamics of downsizing in Australia and New Zealand, Asia Pacific Journal of Human Resources 25(1) (1994), 65-79.

[40] W. McKinley, M.A. Mone and V.L. Barker, Some ideological foundations of organizational downsizing, Journal of Management Inquiry 7(3) (1998), 198-212.

[41] G.H. Mead, Mind, Self and Society, University of Chicago Press, Chicago, 1934.

[42] G.H. Mead, The Social Psychology of G.H. Mead, A. Strauss, ed., University of Chicago Press, Chicago, 1956.

[43] T. Parsons, The Social System, The Free Press, Glencoe, 1951.

[44] T. Parsons, Theories of Society, The Free Press, Glencoe, 1961.

[45] T. Parsons, Social Systems and the Evolution of Action Theory, The Free Press, New York, NY, 1977.

[46] E. Penrose, Theory of the Growth of the Firm, 2nd edn, Basil Blackwell, London, 1980.
[47] P.A. Sorokin, Reconstruction of Humanity, Periodicals Service Co., London, 1974.

[48] P. Sparrow, New organisational forms, processes, jobs and psychological contracts: resolving the HRM issues, in: $\mathrm{Hu}$ man Resource Management: The New Agenda, P. Sparrow and M. Marchington, eds, Pitman, London, 1998.

[49] J. Sutherland, Workforce reduction strategies: an empirical examination of the options, Employee Relations 20(2) (1998), 148-163.

[50] R.I. Sutton, The process of organizational death: Disbanding and reconnecting, Administrative Science Quarterly 32(4) (1987), 542-569.

[51] Swedish National Labour Market Administration (AMV), Varselstatistik 2004 (Lay-off statistics). Arbetsmarknadsstyrelsen (AMS) i Sverige. 2004.

[52] P. Reason and H. Bradbury, Handbook of Action Research: Participatory Inquiry and Practice, Sage, London, 2001.

[53] L. Thurow, The Future of Capitalism: How Today's Economic Forces Shape Tomorrow's World, Allen and Unwin, St. Leonards, Melbourne, 1996.

[54] L. von Bertalanffy, General Systems Theory, Braziller, New York, 1968.

[55] A.R. Weber and D.P. Taylor, Procedures for employee displacement: Advance notice of plant shutdown, The Journal of Business 36(3) (1963), 302-315.

[56] M. Webber and I. Campbell, Labour market outcomes among retrenched workers in Australia, Australia and New Zealand Journal of Sociology 33(2) (1997), 188-204.

[57] N. Wiener, The Human Use of Human Beings: Cybernetics and Society, Da Capo, London, 1954.

[58] R. Wigblad, Community turnarounds in declining company towns: A restructuring model, The Journal of Socio-Economics 24(3) (1995), 463-475.

[59] R. Wigblad, Productivity increases under extreme conditions in contexts without investments, Working Paper, Department of Economics, Statistics and ADB (ESA), Örebro University College, 1998

[60] R. Wigblad, Wage Earners Report, Review of Fundia AB's report on the consequences of a concentration of wire rod production to Mo i Rana, 1999.

[61] R. Wigblad, Industrial relations and productivity in decline, in: European Labour Relations, G. Szell, ed., Vol. II, Gower Publishing, London, 2001.

[62] F. Znaniecki, The Social Role of the Man of Knowledge, Harper and Row, New York, 1968. 